Review article

\title{
The timing of hibernation in Tasmanian echidnas: why do they do it when they do?
}

\author{
Stewart Nicol*, Niels A. Andersen \\ Anatomy and Physiology, University of Tasmania, G.P.O. Box 252-24, Hobart, Tasmania 7001, Australia
}

Received 9 April 2001; received in revised form 18 August 2001; accepted 22 August 2001

\begin{abstract}
We investigated the patterns of hibernation and arousals in seven free-ranging echidnas Tachyglossus aculeatus setosus (two male, five female) in Tasmania using implanted temperature data loggers. All echidnas showed a 'classical' pattern of mammalian hibernation, with bouts of deep torpor interrupted by periodic arousals to euthermia (mean duration $1.04 \pm 0.05(n=146)$. Torpor bout length increased as body temperature fell during the hibernation season, and became more variable as temperature rose again. Hibernation started in late summer (February $28 \pm 5$ days, $n=6$ ) and males aroused just before the winter solstice (June $15 \pm 3$ days, $n=3$ ), females that subsequently produced young aroused 40 days later (July $25 \pm 3, n=4$ ) while females that did not produce young hibernated for a further two months (arousal Sept $27 \pm 5, n=7)$. We suggest that hibernation in Tasmanian echidnas can be divided into two phases, the first phase, marked by declining minimum body temperatures as ambient temperature falls, appears to be obligatory for all animals, while the second phase is 'optional' and is utilised to varying amounts by females. We suggest that early arousal and breeding is the favoured option for females in good condition, and that the ability to completely omit breeding in some years, and hibernate through to spring is an adaptation to an uncertain climate. (c) 2002 Elsevier Science Inc. All rights reserved.
\end{abstract}

Keywords: Echidna; Hibernation; Torpor; Energetics; Monotreme; Reproduction; Body temperature; Climate; Tachyglossus aculeatus

\section{Introduction}

Although the first study of the thermal and metabolic physiology of echidnas (Tachyglossus aculeatus) noted that they hibernated (Martin, 1902), interpretations of the significance of hibernation to echidnas have varied since then. Martin (1902) argued that the low body temperature, low metabolic rate and use of hibernation were related

\footnotetext{
This paper was originally presented at the Cambridge 2000 symposium 'Physiological and Biological Adaptations to Australasian and Southern African Environments' held in Cambridge, July 30-August 3, 2000.

*Corresponding author. Tel.: +61-3-6226-2678; fax: +613-6226-2679.

E-mail address: s.c.nicol@utas.edu.au (S. Nicol).
}

phenomena and reflected the fact that monotremes were primitive mammals and hence imperfect homeotherms. Hibernation is a seasonal phenomenon characterised by $T_{\mathrm{b}}$ values below $10{ }^{\circ} \mathrm{C}$ and torpor bouts of several days or weeks (Geiser and Ruf, 1995), and as studies on hibernating mammals expanded it became clear that hibernation is under precise physiological control, rather than representing an abandonment or overwhelming of homeothermy (Lyman, 1982) and it is now considered to be a 'sophisticated adaptation to the environment of particular endothermic groups or species' (Geiser, 1998). Although Augee et al. (1970) were unable to get captive echidnas to hibernate normally, leading Augee (1978) to con- 
clude that they were not true hibernators, subsequent field studies have demonstrated that this conclusion was mistaken. Echidnas from a range of climatic zones (New England Tablelands, northern NSW, Smith et al., 1989; Western Australian wheat belt, Abensperg-Traun and De Boer, 1992; and Kangaroo Island, South Australia, Green et al., 1992a,b) reduce their activity greatly in winter. When $T_{\mathrm{b}}$ values have been recorded in areas where mean minimum temperatures in winter fall to $5{ }^{\circ} \mathrm{C}$ or lower (Australian Alps, Grigg et al., 1992, 1989; Tasmania, Nicol and Andersen, 1996; New England Tablelands, Falkenstein et al., 1999; south-east Queensland, Beard and Grigg, 2000) echidnas demonstrate a pattern of hibernation which closely resembles deep hibernation in other mammals: periods of deep torpor in which body temperatures fall to approximately $0.5{ }^{\circ} \mathrm{C}$ above ground temperature are broken by periodic arousals to normothermia. On Kangaroo Island, which is the mildest climatic area from which echidna $T_{\mathrm{b}}$ data are available, (average minimum air temperatures in winter are $9{ }^{\circ} \mathrm{C}$ ), Rismiller and McKelvey (1996) found minimum $T_{\mathrm{b}}$ values of approximately $11{ }^{\circ} \mathrm{C}$, and, compared to other areas, a later and much reduced hibernation period, with a small number of torpor bouts.

The fact that echidnas from all climatic zones in which they have been studied appear to show torpor or hibernation raises important questions about the ecological and evolutionary significance of hibernation in this species. Such questions are intensified by the fact that the very low metabolic rate of echidnas means that the energy savings of hibernation are less than in similar sized eutherian hibernators, while the costs of the periodic arousals are proportionately higher (Nicol and Andersen, 1993).

A number of authors have recently discussed the idea that the unpredictable Australian climate has selected for animals with low metabolic rates (Milewski et al., 1994; Flannery, 1994), and we have previously suggested that hibernation in the echidnas is an extension of this selection (Nicol and Andersen, 1996). Lovegrove (1996, 2000) has used statistical techniques to demonstrate that mammals which inhabit zoogeographical zones with unpredictable climate and rainfall (the Australian, Afrotropical, and Indomalaysian zones) generally have low metabolic rates, and also suggests that these mammals are the most likely to employ the strategies of torpor and hibernation.
In order to gain more insight into the role of hibernation in the life history of the echidna we have used implantable temperature data loggers to investigate in detail the pattern of hibernation and arousal in free-ranging Tasmanian echidnas (Tachyglossus aculeatus setosus).

\section{Materials and methods}

Fieldwork was carried out at a sheep grazing property $55 \mathrm{~km}$ north of Hobart. In Tasmania echidnas are predominantly diurnally active, and animals were initially found while they were foraging either in pasture areas, or in patches of dry sclerophyll forest, by slowly driving around the property in a $4 \mathrm{WD}$ vehicle, and then capturing them by hand. All captured animals were tagged used passive implantable transponder tags (Destron-Fearing, Life Chip). Seven echidnas (two males, five females) were taken to the University in Hobart where, under halothane anaesthesia, each was implanted intraperitoneally with a temperature data logger (1996 only Zelcon Technic ZBT5, all others, Onset Computer Corporation, Stowaway Tidbit), and a radiotracking transmitter (Biotelemetry Tracking) glued to the spines on the back. Loggers were calibrated over the range $5-35{ }^{\circ} \mathrm{C}$ and set to record at 60- or 96-min intervals. After recovery animals were returned to the point of capture. When possible females were examined to check for the presence of an egg or young in the pouch, or for signs of lactation. After approximately 12 months animals were captured and the data logger exchanged.

Unless otherwise indicated, values are given as mean \pm S.E., with $n$, the number of observations shown in brackets; number of animals is shown as $N$.

\section{Results}

A total of 14 echidna years of data were obtained from the seven animals. Because data from 1996 were collected using a different logging system and could not be analysed with the other data, 13 echidna years of data have been analysed. All echidnas observed in the field entered hibernation each year. Fig. 1 shows 4 years of body temperature records from echidnas in the study area, while Fig. 2 shows 4 consecutive years from one female. The data logger recordings confirm previous observations that echidnas are 'classical' 


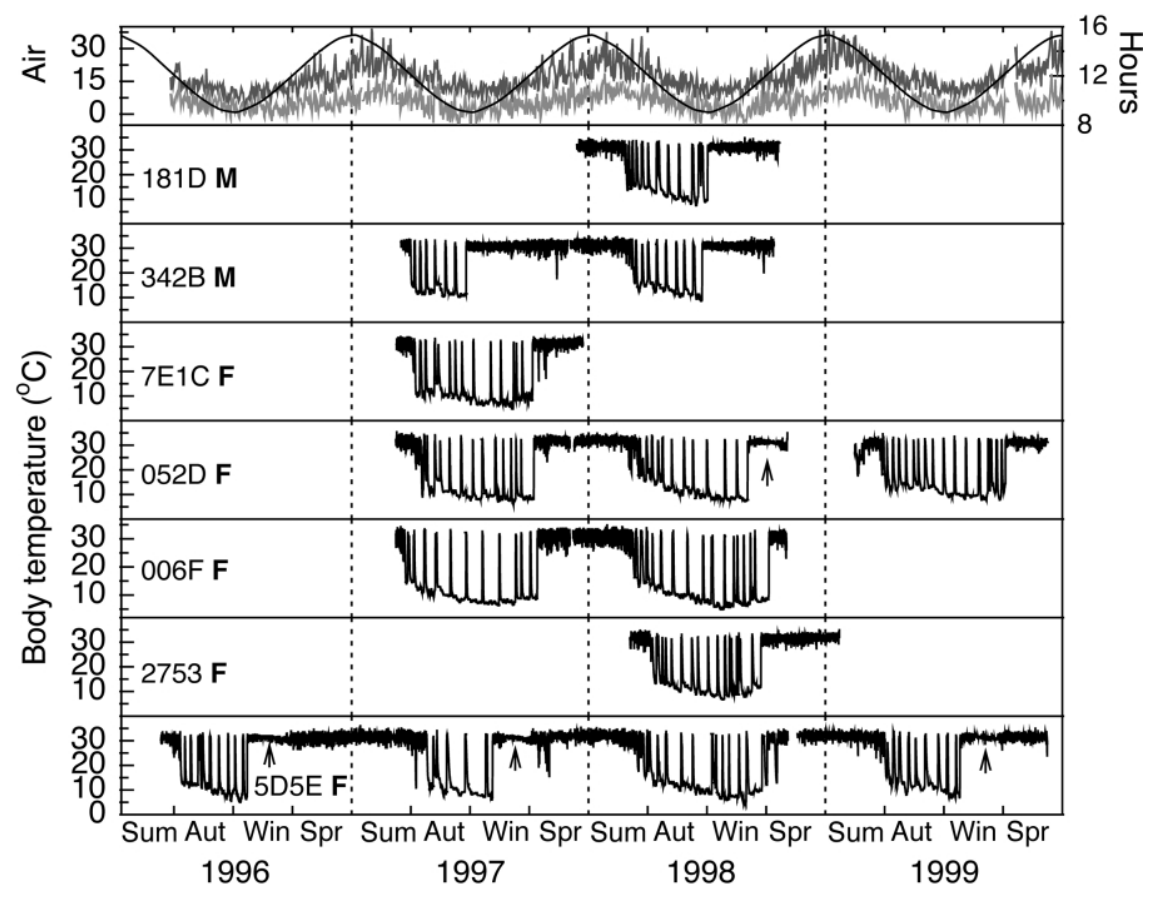

Fig. 1. Body temperature recordings of seven free ranging echidnas (two male: M, five female: F) over 4 years. The top panel shows day length (solid line) and maximum and minimum air temperatures (grey lines). Breaks in the records are due to changeover of data loggers. Arrows indicate period of low variability in $T_{\mathrm{b}}$ associated with incubation (see text and Fig. 2). Seasons for each year are shown with summer starting at the solstice (December 22).

hibernators (Grigg et al., 1989, 1992; Grigg and Beard, 2000; Nicol and Andersen, 1996, 2000), with bouts of deep torpor broken by periodic arousals to euthermia.

\subsection{Entry into hibernation}

Fig. 1 shows that echidnas in this study entered hibernation between February 14 and April 14. Entry into hibernation is not a clear cut event; some animals showed drops to hibernating temperatures, but then returned to the non-hibernating temperature pattern for days or weeks (e.g. 5D5E in 1997). Animals were considered to have entered hibernation when any subsequent periods of normothermia did not exceed 2 days. As we had not anticipated such early entry some animals had been implanted with data loggers in February, while later in the study some animals were not recaptured until late summer, or had young, so that data loggers could not be implanted earlier. Animals which were implanted in February entered hibernation later than animals that had been implanted earlier (mean difference $=28$ days, $t_{12}=$ 4.6; $P<0.001$ in unpaired $t$-test) and so we have excluded dates of entry of these animals from our analysis. This leaves only six reliable data points (two male, four female) which give the mean date of entry as February $28 \pm 5$ days. Although this limited data set does not show any difference in entry date between males and females our field observations suggest that males enter hibernation earlier than females.

\subsection{Arousal from hibernation}

Although entry into hibernation was clearly affected by late implantation of data loggers, there was no discernible effect on final arousal date $\left(t_{12}=0.61 ; P=0.6\right)$. ANOVA and post-hoc testing (Tukey HSD) showed significant differences $(P<$ 0.01 or better) between females which produced young in the subsequent breeding season, females which did not produce young, and males (Table 1).

\subsection{Torpor bouts and periodic arousals}

For the animals recorded over 1997-1999 mean length of hibernation bouts was $11.3 \pm 0.5$ days 


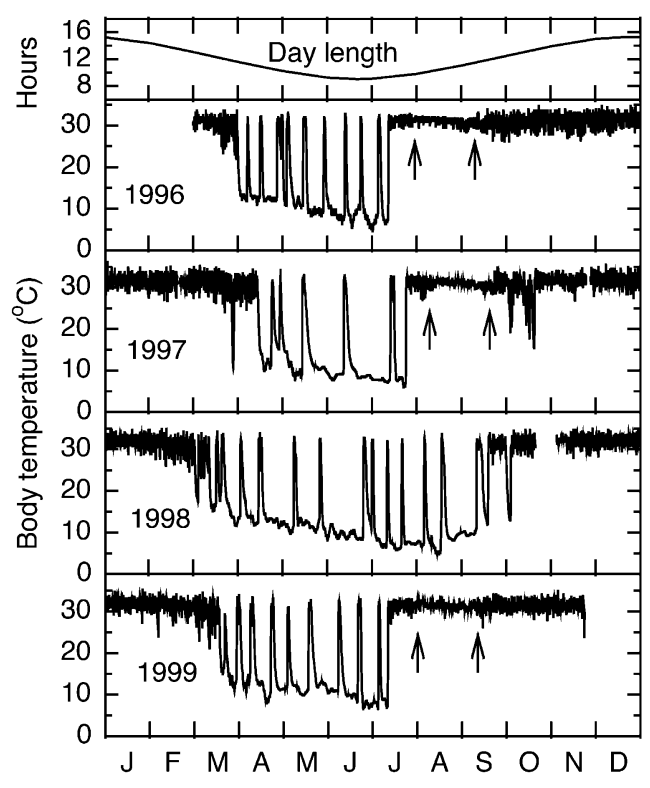

Fig. 2. Four consecutive years of body temperature records from female echidna 5D5E. Because data loggers were implanted in February in 1996 and 1997 the start of hibernation appears more abrupt than in 1998 and 1999 and may have been delayed in these first 2 years. Note the periods of low variability in $T_{\mathrm{b}}$ bracketed by arrows after the mid-winter final arousals in 1996 (July 25), 1997 (July 22) and 1999 (July 13), when young were produced. In 1998 the arousal was 12 weeks later (October 10), and no young was produced.

$n=167, N=7)$, the mean euthermic interval was $1.04 \pm 0.05$ days $(n=146)$, and mean number of bouts in a hibernation season was $12.8 \pm 1.0,(n=$ 13, range 7-18), and mean minimum $T_{\mathrm{b}}$ was $7.9 \pm 0.4{ }^{\circ} \mathrm{C}(n=13)$. The mean time to arouse was $8.8 \pm 0.3 \mathrm{~h}(n=134)$. Time to arouse was dependent on $T_{\mathrm{b}}$ and was described by the regression: arousal time $(\mathrm{h})=13.1-0.38 T_{\mathrm{b}}, r=0.39$, $P<0.00001$.

Figs. 1 and 2 show that the hibernation season in echidnas can be divided into two phases: in the first phase body temperature falls as ambient temperatures fall and torpor bouts progressively increase in length, while in the second phase body temperature rises, and arousals become more frequent. Some echidnas show only the first phase, or have a very truncated second phase, while females which do not arouse early and mate show a lengthy second phase. To test whether there were real differences between these two phases, torpor bout length and euthermic interval were compared between the two phases. Phase 2 was defined as beginning when the average $T_{\mathrm{b}}$ during a torpor bout was higher than in the previous bout. An unpaired $t$-test indicated no significant difference between bout lengths in each phase $\left(t_{165}=1.8\right.$; $P=0.07$ ), while euthermic intervals in the second phase were slightly shorter $\left(t_{144}=2.5 ; P<0.02\right)$. However, as both of these parameters correlated strongly with $T_{\mathrm{b}}$, and as mean $T_{\mathrm{b}}$ was significantly different between the phases $\left(t_{163}=3.83 ; P<\right.$ 0.0002 ) analyses of variance of these data were carried out with $T_{\mathrm{b}}$ as a covariate to determine whether their was any difference between the two phases, other than that related to differences in $T_{\mathrm{b}}$. Additionally, as hibernating $T_{\mathrm{b}}$ during the early parts of the first phase was generally higher than in any parts of the second phase, comparisons were only made for bouts where $T_{\mathrm{b}}$ was less than $14{ }^{\circ} \mathrm{C}$. These analyses showed that bout lengths were significantly longer in the first phase of hibernation than in the second $\left(F_{1,128}=22 ; P<\right.$ $0.00001)$ whereas there was no significant difference in euthermic interval $\left(F_{1,120}=1.0 ; P=0.3\right)$. Although these data were made up of different numbers of bouts for different animals, and include data from several years for some echidnas, there was no significant difference between animals $\left(F_{6,120}=1.4, P=0.2\right.$, for phase 1$)$ or years $\left(F_{2,120}=\right.$ $1.3 ; P=0.28)$.

Fig. 3 shows bout lengths and $T_{\mathrm{b}}$ plotted for each month, and clearly demonstrates the difference between the two phases. While there appears to be a close relationship between body temperature and bout length in the first phase, this is not as apparent in the second phase. Comparison of

Table 1

Date of end of hibernation season for three classes of adult echidnas: females which did not produce young during the breeding season following arousal, females which produced young, and males

\begin{tabular}{|c|c|c|}
\hline & $\begin{array}{l}\text { Mean arousal date } \\
\pm \text { S.D. }(n)\end{array}$ & $\begin{array}{l}\text { Days after winter } \\
\text { solstice (21 June) }\end{array}$ \\
\hline Females without young & Sept $27 \pm 5(7)$ & 98 \\
\hline Females with young & July $25 \pm 9$ & 35 \\
\hline Males & June $15 \pm 3$ (3) & -5 \\
\hline
\end{tabular}




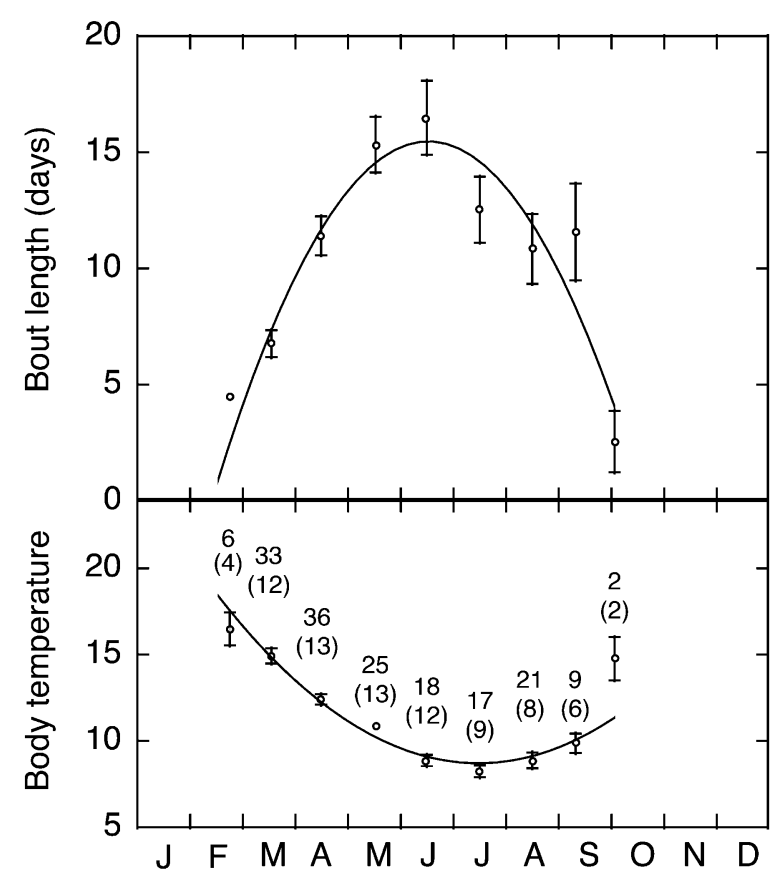

Fig. 3. Hibernation bout length and body temperature of seven echidnas shown in Fig. 1 during, 1997-1999. Values shown are means for each month, bars show standard error. Figures above the temperature curve are the number of bouts contributing to the monthly mean $(n)$, with the number of animals $(N)$ shown in brackets. When the same animals have contributed to the data for both years these have been counted as though they were different animals, so maximum $n=13$. Curves are second order polynomials fitted to all data. Body temperatures are the average for the torpor period preceding the arousal.

the data for June and August, for example, shows that although $T_{\mathrm{b}}$ values are not significantly different (June: $8.9 \pm 0.33{ }^{\circ} \mathrm{C}$, August: $8.9 \pm 0.48{ }^{\circ} \mathrm{C}$; $t_{36}=0.002 ; P=0.99$ ), bout length in August is significantly shorter (June: $16.5 \pm 1.6$ days, August: $10.8 \pm 1.5$ days; $t_{37}=2.6 ; P=0.014$ ).

On four occasions females produced young; one female (5D5E, see Figs. 1 and 2) produced young in 3 of the 4 years for which data are shown (1996, 1997 and 1999), while 052D produced an offspring in 1998. During the period of incubation of the egg and the first few weeks of incubation of the young there is a reduction in variability of the mother's body temperature (Andersen and Nicol, in preparation), which can be seen on Figs. 1 and 2. This and our direct observations indicate that in Tasmania females mate within a few days of arousal from hibernation (Andersen and Nicol, in preparation).

\section{Discussion}

The role of the periodic arousals shown by all hibernators is the subject of continuing debate. Barnes et al. (1993) and Heller et al. (1993) have suggested that the arousals are necessary so that normal sleep can occur, while earlier suggestions include the excretion of accumulated metabolic waste products, and depletion of energy reserves (see Geiser et al., 1990). There is strong evidence in some hibernators at least that timing of the final spring arousal depends on the weather conditions, and that during arousals even hibernators that are confined to underground burrows assess the environmental conditions at or near the entrance to their dens (French, 1988; French and Forand, 2000). Echidnas do not construct a complex hibernaculum, (although some mothers dig a nursery burrow after mating) and in our study area were found to hibernate in piles of bark, hollow logs, $\log$ windrows, refuges under rocks, and grass tussocks, or simply dug into the soil. During periodic arousals some echidnas move to another site, and could utilise the arousals to check the environment. Inspection of Figs. 1 and 2 suggests that mature females may 'decide' during any of the arousals after the solstice not to re-enter hibernation - this decision is presumably affected by the condition of the animal, including energy reserves, and possibly the availability of males. Arousals are often triggered by rises in ambient temperature during brief warm spells, with the consequence that echidnas in the same area tend to arouse at the same time (Nicol and Andersen, 2000), which would facilitate interaction.

\subsection{Timing of hibernation}

At first inspection the date of entry into hibernation seems quite early (mean date is February $28 \pm 5$ days, with the earliest in Fig. 1 being February 15), which means that ambient temperatures are near their highest for the year. To simplify comparison between northern and southern hemisphere data, entry date has been recalculated as days after the summer solstice (taken as December 22 in the southern hemisphere, and 21 June in the northern hemisphere). Thus from our data Tasmanian echidnas enter hibernation $68 \pm 5$ days after the summer solstice. A search of the literature shows that, amongst the intensively studied sciurid rodent hibernators, some enter hiber- 
nation at a corresponding time of the year. Reproductive female golden-mantled ground squirrels (Spermophilus saturatus) in Washington State entered hibernation $65 \pm 2$ days after the summer solstice (Kenagy et al., 1990), adult female arctic ground squirrels $(S$. parryi) entered hibernation at 62 days (Buck and Barnes, 1999), and yellow bellied marmots (Marmota flaviventris) in Colorado at 72 days (Armitage, 1998). While many species may enter hibernation later than this, early entry into hibernation is not an unique strategy. What is unique in the echidna is the early arousal from hibernation, particularly of the males which in this study aroused on average 5 days before the winter solstice (Table 1). For the sciurid hibernators listed above hibernation ends approximately 112,131 and 130 days, respectively, after the winter solstice, and the average arousal date for hibernators would be mid-spring. The other Australian hibernator for which field data are available is the mountain-pygmy possum (Burramys parvus) which hibernates from April-May through to September-October, i.e. from approximately 130 days after the summer solstice to 100 days after the winter solstice (Kortner and Geiser, 1998) and in this respect is a 'typical' hibernator. Data from echidnas in the Australian Alps in Southern New South Wales which were fitted with temperature sensitive transmitters (Beard et al., 1992), despite some uncertainties about the exact time of entry and arousal, are consistent with our observations, as are data from the New England plateau in northern New South Wales (Falkenstein et al., 1999, Geiser, personal communication) and southeast Queensland (Beard and Grigg, 2000).

In many sciurid hibernators reproductive males are the first to arouse from hibernation, probably to allow spermatogenesis to occur (Barnes, 1996). In Arctic ground squirrels the mean difference between the first animals to emerge (reproductive males) and the last to emerge (non-reproductive males) is approximately 2 weeks (Buck and Barnes, 1999). Although most marmots are communal hibernators (Arnold, 1993) and arouse closely together (Ruf and Arnold, 2000), woodchucks (M. monax) are solitary hibernators and southern woodchuck (M. monax monax) males arouse 3 weeks before females and subadult males (Snyder and Christian, 1960). The 30-day difference between arousal of male and breeding female echidnas in this study (Table 1), may reflect a requirement for a period of euthermia for spermat- ogenesis to occur, and also strong selective pressures for males to be active when the first females appear. As noted above, female echidnas in Tasmania appear to mate within a few days of arousal, and so males will need to be prepared early. However, unlike the sciurids, in which arousal dates of breeding and non-breeding (juvenile) animals differ by no more than 3 weeks, breeding female echidnas in this study aroused 2 months before non-breeding females. Perhaps more significantly, in sciurids all adult females arouse at the same time while reproductively mature female echidnas vary their length of hibernation between breeding and non-breeding years. Relatively shortlived animals like rodents may not be able to afford to miss a breeding season when they have so few - in a 10-year study of $M$. flaviventris the oldest females found were 7 years old, and at the time of first breeding yearling females had an average life expectancy of 2 years (Armitage and Downhower, 1974). Although there are not yet comparable data for echidnas, they are very longlived (Rismiller and McKelvey, 2000), and Rismiller (1999) reports that one free ranging echidna was sighted for 45 years.

Why do breeding echidnas arouse from hibernation so early? We suggest that the arousal of echidnas to mate at the coldest time of the year paradoxically reflects the fact that they have been selected to minimise energy expenditure. Selective pressures which have lead to hibernation in echidnas appear very different from the factors that have selected for hibernation in Nearctic and Palaearctic mammals such as sciurids, in which hibernation occurs in response to a predictable resource shortage in winter. This is followed by a period of reproduction and rapid growth of young in spring, in which there is a high probability that there will be suitable conditions for producing young. The review of life history data for 25 sciurid species by Blumstein and Armitage (1998) shows an average litter size of five being weaned after a gestation period of 28 days and a lactation period of 35 days. The short period of gestation and lactation is one of very high metabolic activity in these Nearctic hibernators. In golden-mantled ground squirrels (S. saturatus) litter mass is $10 \%$ of maternal weight (Kenagy et al., 1989) and the average daily energy expenditure for lactating females with five young is 3.7 times BMR, near the theoretical maximal daily sustained energy output for this species (Kenagy et al., 1990). 
The echidna also has a very short gestation period (22-24 days gestation between mating and egg-laying and a further 10 days until hatching, Griffiths, 1978; Rismiller and McKelvey, 2000), but in other respects is very different from the sciurids. At hatching the echidna young is approximately $300 \pm 45 \mathrm{mg}$ (Rismiller and McKelvey, 2000) - approximately $1 / 10$ thousandth of the size of the mother. By 30 days the weight is approximately $90 \mathrm{~g}$, representing only an additional $15 \%$ increase in maternal energy expenditure over the field metabolic rate of non-lactating animals (Green et al., 1992a,b). In fact echidnas appear to follow a strategy of depressed initial investment, similar to that followed by some marsupials, which Low (1978) has pointed out is highly successful in unpredictable environments. If young are lost during their first month or so then this does not entail as great a loss of maternal energy investment as is the case in sciurids. However, because the rate of transfer of energy from the echidna mother to young is initially so low, compared with sciurids, the overall period of dependence on the mother during lactation is much longer. Lactation times in Tasmanian echidnas have not been accurately measured, but are likely to be approximately 200 days, based on data from echidnas in Kangaroo Island (Rismiller and McKelvey, 2000). Although the breeding events shown in Figs. 1 and 2 are very early in the year mating is spread over the period July-October (Andersen and Nicol, in preparation). Late matings are probably less common, and may occur following the loss of a young (Beard and Grigg, 2000), but there is as yet little data. Survival of young born at different times of the year is presumably strongly dependent on weather and food availability that season. In a good year, young which result from early matings should be best placed to be weaned and gain sufficient weight to survive the next winter, but at this stage we do not have data on the relationship between breeding time, weather and survival and recruitment of the young. The only published study of recruitment in echidnas was carried out on the Kangaroo Island subspecies (Tachyglossus aculeatus multiaculeatus, Rismiller and McKelvey, 2000). Twenty-five female echidnas were followed for up to 7 years, and in the observed total of 81 echidna breeding years only 22 hatchlings were produced, and of these only 8 survived to weaning. Rismiller and McKelvey (2000) estimated that mature females on Kangaroo
Island produced young every 4-6 years but there seem to be a number of differences between Kangaroo Island echidnas and the Tasmanian subspecies (T. aculeatus setosus). Tasmanian echidnas show deep hibernation with all animals apparently hibernating in the period March-June, and in the examples we have documented, mating within 1 or 2 days of the end of hibernation (Andersen and Nicol, in preparation). In the Australian Alps all echidnas studied by Grigg et al. (1992) hibernated, and mating occurred within days of arousal (Beard et al., 1992. By contrast Rismiller and McKelvey (1996) report that on Kangaroo Island there was no time in winter when all echidnas were inactive, and although breeding also began at the end of June, it ended in July, while courtship durations ranged from 7 to 37 days (Rismiller and McKelvey, 2000). The two animals (one male, one female) from Kangaroo Island from which Rismiller and McKelvey (1996) obtained $T_{\mathrm{b}}$ data although sexually mature did not reproduce in the years they were recorded, and it may be that on Kangaroo Island only non-reproducing animals hibernate. These animals showed on average three bouts of torpor with a minimum $T_{\mathrm{b}}$ of $12.6 \pm 0.3$ ${ }^{\circ} \mathrm{C}$. Torpor bouts were much shorter (1-10 days), and intervening periods of euthermia were longer (1-5 days) than in our results.

We suggest that hibernation in Tasmanian echidnas can be divided into two phases; the first phase, marked by declining minimum body temperatures, appears to be obligatory for all animals, while the second phase when minimum temperature levels out and then begins to rise as ambient temperature rises, is 'optional' and Fig. 3 (and the statistical analysis) shows that the difference between these phases is not simply a function of $T_{\mathrm{b}}$, and animals arouse more frequently after July. In this study males hibernated only for the obligatory period, while females showed varying lengths of the 'optional' phase. It seems likely that early breeding would be the favoured strategy for females in good condition, while females that are in poorer condition may breed later in the year, when more food is available, but with the risk that young may be too small to survive the next winter. Staggered breeding may be a strategy employed principally in colder parts of the echidna's range, but much more field data are required from different climatic zones, before all the factors affecting breeding and hibernation can be understood. The ability to vary the length of hibernation by 2 months allows 
females to reduce energy expenditure in adverse years when resource availability or climatic conditions are unfavourable for breeding.

Grigg and Beard (2000) have suggested that echidnas 'use cold as a resource', taking advantage of the colder months to benefit from the energy savings produced by a low body temperature. In cold conditions hibernators save energy by not employing thermoregulation, and after a period of metabolic suppression which allows body temperature to fall, allow body temperature to stay close to ambient. The lower the body temperature (down to a limit that varies between species) the lower the metabolic rate, and the greater the energy savings. However, if echidnas were seeking to maximise their use of cold as a resource, we would expect them to hibernate over the coldest part of the year, rather than enter hibernation when temperatures are relatively high, and arouse mid-winter (Figs. 1 and 2).

In fact it seems that echidna throughout their range become torpid in the period FebruarySeptember (Nicol and Andersen, 1996; Rismiller and McKelvey, 1996; Grigg and Beard, 2000) but it is only where the ambient temperature remains consistently low that we see sustained periods of deep hibernation. It is possible that in areas with mild winters, such as Kangaroo Island, the obligatory phase of hibernation is greatly reduced, and that hibernation is essentially optional. It does seem reasonable to interpret hibernation in echidnas as part of an overall low energy strategy which is made possible by other aspects of their physiology, such as a short gestation period.

Much more field data are required if we are to understand more fully how factors such as food supply, climatic variation and interaction between echidnas affect the length of hibernation and the timing of reproduction. Several specific questions that need to be answered are: Is it only animals that arouse from hibernation late or lose their first young that breed late? What physiological or environmental factors determine whether an individual arouses early or late? What are the survival rates of young hatched at different times of the year? For a species of such intrinsic biological interest we are still surprisingly ignorant of many details of its life history.

\section{References}

Abensperg-Traun, M., De Boer, E.S., 1992. The foraging ecology of a termite- and ant-eating specialist, the echidna
Tachyglossus aculeatus (Monotremata: Tachyglossidae). J. Zool. (Lond.) 226, 243-257.

Armitage, K.B., Downhower, J.F., 1974. Demography of yellow-bellied marmot populations. Ecology 55, 1233-1245.

Armitage, K.B., 1998. Reproductive strategies of yellowbellied marmots-energy conservation and differences between the sexes. J. Mamm. 79, 385-393.

Arnold, W., 1993. Energetics of social hibernation. In: Carey, C., Florant, G.L., Wunder, B.A., Horwitz, B. (Eds.), Life in the Cold: Ecological, Physiological and Molecular Mechanisms, Westview Press, Boulder, CO pp. 65-80.

Augee, M.L., 1978. Monotremes and the evolution of homeothermy. In: Augee, M.L. (Ed.), Monotreme Biology, Royal Zoological Society NSW, Mosman pp. 111-121.

Augee, M.L., Ealey, E.H.M., Spencer, H., 1970. Biotelemetry studies of temperature regulation and torpor in the echidna. J. Mamm. 51, 561-570.

Barnes, B.M., 1996. Relationships between hibernation and reproduction in male ground squirrels. In: Geiser, F., Hulbert, A.J., Nicol, S.C. (Eds.), Adaptations to the Cold: Tenth International Hibernation Symposium, University of New England Press, Armidale pp. 71-80.

Barnes, B.M., Omtzigt, C., Daan, S., 1993. Hibernators periodically arouse in order to sleep. In: Carey, C., Florant, G.L., Wunder, B.A., Horwitz, B. (Eds.), Life in the Cold: Ecological, Physiological and Molecular Mechanisms, Westview Press, Boulder, CO pp. 555-558.

Beard, L.A., Grigg, G.C., 2000. Reproduction in the shortbeaked echidnas, Tachyglossus aculeatus: field observations at an elevated site in south-east Queensland. Proc. Linn. Soc. NSW 122, 89-99.

Beard, L.A., Grigg, G.C., Augee, M.L., 1992. Reproduction by echidnas in a cold climate. In: Augee, M.L. (Ed.), Platypus and Echidnas, Royal Zoological Society NSW, Mosman pp. 93-100.

Blumstein, D.T., Armitage, K.B., 1998. Life history consequences of social complexity - a comparative study of ground-dwelling sciurids. Behav. Ecol. 9, 8-19.

Buck, C.L., Barnes, B.M., 1999. Annual cycle of body composition and hibernation in free-living arctic ground squirrels. J. Mamm. 80, 430-442.

Falkenstein, F., Körtner, G., Geiser, F., 1999. Hibernaculum selection and home range of echidnas (Tachyglossus aculeatus) on the New England Tablelands. Australian Mammal Society Proceedings, 41.

Flannery, T., 1994. The Future Eaters. Reed Books, Melbourne.

French, A.R., 1988. The pattern of mammalian hibernation. Am. Sci. 76, 568-575.

French, A.R., Forand, S., 2000. Role of soil temperature in timing of emergence from hibernation in the jumping mouse, Zapus hudsonius. In: Heldmaier, G., Klingenspor, M. (Eds.), Life in the Cold: Eleventh International Hibernation Symposium, Springer, Berlin pp. 111-119.

Geiser, F., 1998. Evolution of daily torpor and hibernation in birds and mammals-importance of body size. Clin. Exp. Pharmacol. Physiol. 25, 736-739.

Geiser, F., Ruf, T., 1995. Hibernation versus daily torpor in mammals and birds: physiological variables and classification of torpor patterns. Physiol. Zool. 68, 935-966.

Geiser, F., Hiebert, S., Kenagy, G.J., 1990. Torpor bout duration during the hibernating season of two sciurid rodents: inter- 
relations with temperature and metabolism. Physiol. Zool. 63, 489-503.

Green, B., Griffiths, M., Newgrain, K., 1992a. Energy costs of lactation in free-living echidnas. In: Augee, M.L. (Ed.), Platypus and Echidnas, Royal Zoological Society NSW, Mosman pp. 90-92.

Green, B., Griffiths, M., Newgrain, K., 1992b. Seasonal patterns in water, sodium and energy turnover in free-living echidnas, Tachyglossus aculeatus (Mammalia: Monotremata). J. Zool. 227, 351-365.

Griffiths, M., 1978. The Biology of Monotremes. Academic Press, New York.

Grigg, G., Beard, L., 2000. Hibernation by echidnas in mild climates: Hints about the evolution of endothermy. In: Heldmaier, G., Klingenspor, M. (Eds.), Life in the Cold: Eleventh International Hibernation Symposium, Springer, Berlin pp. 5-20.

Grigg, G.C., Beard, L.A., Augee, M.L., 1989. Hibernation in a monotreme, the echidna Tachyglossus aculeatus. Comp. Biochem. Physiol. A 92, 609-612.

Grigg, G.C., Augee, M.L., Beard, L.A., 1992. Thermal relations of free-living echidnas during activity and in hibernation in a cold climate. In: Augee, M.L. (Ed.), Platypus and Echidnas, Royal Zoological Society NSW, Mosman pp. 160-173.

Heller, H.C., Grahn, D.A., Tracsel, L., Larkin, J.E., 1993. What is a bout of hibernation? In: Carey, C., Florant, G.L., Wunder, B.A., Horwitz, B. (Eds.), Life in the Cold: Ecological, Physiological and Molecular Mechanisms, Westview Press, Boulder, CO pp. 252-264.

Kenagy, G.J., Stevenson, R.D., Masman, D., 1989. Energy requirements for lactation and postnatal growth in captive golden-mantled ground squirrels. Physiol. Zool. 62, 470-487.

Kenagy, G.J., Masman, D., Sharbaugh, S.M., Nagy, K.A., 1990. Energy expenditure during lactation in relation to litter size in free living golden-mantled ground squirrels. J. Anim. Ecol. 59, 73-88.

Kortner, G., Geiser, F., 1998. Ecology of natural hibernation in the marsupial mountain pygmy-possum (Burramys parvus). Oecologia 113, 170-178.

Lovegrove, B.G., 1996. The low basal metabolic rates of marsupials: the influence of torpor and zoogeography. In: Geiser, F., Hulbert, A.J., Nicol, S.C. (Eds.), Adaptations to the Cold: Tenth International Hibernation Symposium, University of New England Press, Armidale pp. 141-151.

Lovegrove, B.G., 2000. The zoogeography of mammalian basal metabolic rate. Am. Nat. 156, 201-219.
Low, B.S., 1978. Environmental uncertainty and the parental strategies of marsupials and placentals. Am. Nat. 112, 197-213.

Lyman, C.P., 1982. Why bother to hibernate? In: Lyman, C.P., Willis, J.S., Malan, A., Wang, L.C.H. (Eds.), Hibernation and Torpor in Mammals and Birds, Academic Press, New York pp. $1-10$.

Martin, C.J., 1902. Thermal adjustment and respiratory exchange in monotremes and marsupials. Phil. Trans. R. Soc. Lond. Series B: Biol. Sci. 195, 1-37.

Milewski, A.V., Abensperg-Traun, M., Dickman, C.R., 1994. Why are termite- and ant-eating mammals smaller in Australia than in southern Africa; history or ecology? J. Biogeogr. 21, 529-543.

Nicol, S.C., Andersen, N.A., 1993. The physiology of hibernation in an egg-laying mammal, the echidna. In: Carey, C., Florant, G.F., Wunder, B.A., Horwitz, B. (Eds.), Life in the Cold III: Ecological, Physiological, and Molecular Mechanisms, Westview Press, Boulder, CO pp. 55-64.

Nicol, S.C., Andersen, N.A., 1996. Hibernation in the echidna: not an adaptation to cold? In: Geiser, F., Hulbert, A.J., Nicol, S.C. (Eds.), Adaptations to the Cold: Tenth International Hibernation Symposium, University of New England Press, Armidale pp. 7-12.

Nicol, S.C., Andersen, N.A., 2000. Patterns of hibernation of echidnas in Tasmania. In: Heldmaier, G., Klingenspor, M. (Eds.), Life in the Cold: Eleventh International Hibernation Symposium, Springer, Berlin pp. 21-29.

Rismiller, P.D., 1999. The Echidna, Australia's Enigma. Hugh Lauter Levin associates inc, Bridgeport, CT.

Rismiller, P.D., McKelvey, M.W., 1996. Sex, torpor and activity in temperate climate echidnas. In: Geiser, F., Hulbert, A.J., Nicol, S.C. (Eds.), Adaptations to the Cold: Tenth International Hibernation Symposium, University of New England Press, Armidale pp. 23-30.

Rismiller, P.D., McKelvey, M.W., 2000. Frequency of breeding and recruitment in the short-beaked echidna, Tachyglossus aculeatus. J. Mamm. 81, 1-17.

Ruf, T., Arnold, W., 2000. Mechanisms of social thermoregulation in hibernating alpine marmots (Marmota marmota). In: Heldmaier, G., Klingenspor, M. (Eds.), Life in the Cold: Eleventh International Hibernation Symposium, Springer, Berlin pp. 81-94.

Smith, A.P., Wellham, G.S., Green, S.W., 1989. Seasonal foraging activity and microhabitat selection by echidnas (Tachyglossus aculeatus) on the New England Tablelands. Aust. J. Ecol. 14, 457-468.

Snyder, R.L., Christian, J.J., 1960. Reproductive cycle and litter size of the woodchuck. Ecology 41, 647-656. 